\title{
Frequency Dependant and Frequency Independent Selection of Wild Birds When Presented with Artificial Prey and Whether Selection Pressures Are Present
}

\author{
Sarah Jayne Drinkwater \\ Biological Sciences, The Open University, Oxford, United Kingdom
}

Email address:

sarah.jayne.drinkwater@gmail.com

\section{To cite this article:}

Sarah Jayne Drinkwater. Frequency Dependant and Frequency Independent Selection of Wild Birds When Presented with Artificial Prey and Whether Selection Pressures Are Present. American Journal of Bioscience and Bioengineering. Vol. 5, No. 4, 2017, pp. 88-91.

doi: 10.11648/j.bio.20170504.12

Received: September 13, 2017; Accepted: September 27, 2017; Published: November 2, 2017

\begin{abstract}
Genetic variation of a prey population can be affected by a range of variables, one of which is wild birds. Many species of prey population are polymorphic and wild birds hunt by sight which may means they select one morph of their prey over the other. The aim of this investigation is to use artificial prey to examine whether birds in an urban area, such as a garden of a residence, operate via selection pressures. 20 trials in total were performed. 10 trials with 45 yellow balls and 5 red balls were presented (ratio 9 yellow: 1 red) followed by 10 trials of 45 red balls and 5 yellow balls (ratio 9 red: 1 yellow). The bird population showed evidence of operating under significant frequency-dependant selection but not under significant frequency independent selection. The results show we can reject the null hypothesis that wild birds do not exhibit selection preferences due to the colour and frequency of the artificial prey, however, the null hypothesis can be accepted when in reference to frequency dependant selection. The birds showed no preference to which colour was rare, just that if that colour was the rare colour at the time, they select it over the common.
\end{abstract}

Keywords: Genetic Variation, Selection Pressures, Frequency Independent, Dependant, Wild Birds, Artificial Prey, Mann Whitney U Test, Selection

\section{Introduction}

Genetic variation of a prey population can be affected by a range of variables, one of which is wild birds. Many species of prey population are polymorphic and wild birds hunt by sight which may means they select one morph of their prey over the other, especially if one is of a more conspicuous morph [2]. Selection pressures, in this case frequencyindependent selection, may arise from wild birds hunting this way meaning that because the birds choose one morph over another, the morph which is chosen the least is the most likely stay fixed in a population. Boston betularia is an example of frequency-independent prey selection. During the industrial revolution, dark morphs of B.betularia increased in frequency due to being better camouflaged from their prey. However, once pollution levels decreased, dark morphs of B.betularia decreased in frequency. [6]

Predators can also select more common morphs due to preference [9], rather than rare morphs, which can promote polymorphism by increasing the fitness of rare morphs [9] and is known as positive frequency dependant selection. Negative frequency dependant selection can occur when a rare morph is, for example, more conspicuous when surrounded by common morphs so the predators then become fixated on the common morphs.

The hypothesis tested were;

Null hypothesis $\left(\mathrm{H}_{0}\right)$

Wild birds do not exhibit any selection preferences due to the colour or frequency of the artificial prey

Alternative hypothesis $\left(\mathrm{H}_{\mathrm{A}}\right)$

Wild birds do exhibit selection preferences due to the colour and frequency of the artificial prey.

The aim of this investigation is to examine whether birds in an urban area, such as a garden of a residence, operate via selection pressures. To do this birds will be presented with 2 different morphs of artificial food, in this case balls of dough 
which only differ in their colour, and the results will then be investigated against the null hypothesis using Mann Whitney $\mathrm{U}$ [7] statistical test as to whether frequency dependant or frequency independent selection is present. The potential long term evolutionary implications on prey insects and berries is also discussed.

\section{Methods}

The experiment was carried out using the instructions in the S317 module materials as a guide [1], in a garden in Zandvoort, Netherlands from 1st January 2016-22nd January 2016. The instructions were to create red and yellow dough balls to use as artificial prey for birds in the garden of residence or park. The instructions stated that we were to use the dough balls for one week to get the birds used to artificial prey before the experiment begun.

The recipe for the dough balls is as follows:

$750 \mathrm{~g}$ flour

$250 \mathrm{~g}$ butter

Water

Yellow and red colouring

The coloured dough balls of equal size were presented in red and yellow on a $20 \mathrm{~cm}$ by $10 \mathrm{~cm}$ platform which was positioned on a raised window ledge. Other experiments of this type have used pastry as their artificial prey [4] S. merilaita [10] used a simulation model for their research.

The investigation involved 20 trials in total. 10 trials with 45 yellow balls and 5 red balls were presented (ratio 9 yellow: 1 red) followed by 10 trails of 45 red balls and 5 yellow balls (ratio 9 red: 1 yellow). The platform was checked every 45 minutes and each trial was replaced once no less than 15 but no more than 35 balls were left over. Data for the number of each colour left was recorded in a spreadsheet provided by The Open University [1]. $\beta$ values were calculated using the number of coloured dough balls remaining from the trials the spreadsheet provided by The Open University [1] and those $\beta$ values were then used to find median value of the $\beta$ values. Using the null hypothesis, a statistical test [7] was then done assess the significance of any differences in $\beta$-values.

The most common species of bird that were observed to take the dough were eurasian curlew (Numenius arquata), magpies (Pica pica) and tree pipits (Anthus trivialis). Eurasian collared doves (Streptopelia decaocto) were also spotted taking dough on 6 different trials. [8]

\section{Results}

The results of the trials (figure 1)

\section{S317 Bird Predation Experiment}

Red Common

\begin{tabular}{|c|c|c|c|c|c|c|c|}
\hline $\begin{array}{c}\text { Trial } \\
\text { no. }\end{array}$ & $\begin{array}{c}\boldsymbol{Y} \\
\text { (yellow } \\
\text { presented) }\end{array}$ & $\begin{array}{c}\boldsymbol{y} \\
\text { (yellow } \\
\text { remaining) }\end{array}$ & $\begin{array}{c}\text { Yellow } \\
\text { taken }\end{array}$ & $\begin{array}{c}\boldsymbol{R} \\
(\text { red } \\
\text { presented) }\end{array}$ & $\begin{array}{c}\boldsymbol{r} \\
\text { (red } \\
\text { remaining) }\end{array}$ & red taken & $\begin{array}{c}\text { 'Total } \\
\text { remaining }\end{array}$ \\
\hline 1 & 5 & 1 & 4 & 45 & 19 & 26 & 20 \\
\hline 2 & 5 & 0 & 5 & 45 & 23 & 22 & 23 \\
\hline 3 & 5 & 1 & 4 & 45 & 17 & 28 & 18 \\
\hline 4 & 5 & 2 & 3 & 45 & 19 & 26 & 21 \\
\hline 5 & 5 & 1 & 4 & 45 & 27 & 18 & 28 \\
\hline 6 & 5 & 0 & 5 & 45 & 22 & 23 & 22 \\
\hline 7 & 5 & 0 & 5 & 45 & 17 & 28 & 17 \\
\hline 8 & 5 & 0 & 5 & 45 & 19 & 26 & 19 \\
\hline 9 & 5 & 1 & 4 & 45 & 27 & 18 & 28 \\
\hline 10 & 5 & 1 & 4 & 45 & 24 & 21 & 25 \\
\hline
\end{tabular}

\begin{tabular}{|c|c|}
\hline $\begin{array}{c}\beta_{y} \\
\text { rare }\end{array}$ & $\begin{array}{c}\beta_{r} \\
\text { commo }\end{array}$ \\
\hline 0.651 & 0.349 \\
\hline 0.727 & 0.273 \\
\hline 0.623 & 0.377 \\
\hline 0.515 & 0.485 \\
\hline 0.759 & 0.241 \\
\hline 0.715 & 0.285 \\
\hline 0.648 & 0.352 \\
\hline 0.675 & 0.325 \\
\hline 0.759 & 0.241 \\
\hline 0.719 & 0.281 \\
\hline
\end{tabular}

\section{Yellow Common}

\begin{tabular}{|c|c|c|c|c|c|c|c|}
\hline $\begin{array}{c}\text { Trial } \\
\text { no. }\end{array}$ & $\begin{array}{c}Y \\
\text { (yellow } \\
\text { presented) }\end{array}$ & $\begin{array}{c}\boldsymbol{y} \\
\text { (yellow } \\
\text { remaining) }\end{array}$ & $\begin{array}{c}\text { Yellow } \\
\text { taken }\end{array}$ & $\begin{array}{c}\boldsymbol{R} \\
\text { (red } \\
\text { presented) }\end{array}$ & $\begin{array}{c}r \\
\text { (red } \\
\text { remaining) }\end{array}$ & red taken & $\begin{array}{c}\text { 'Total } \\
\text { remaining }\end{array}$ \\
\hline 1 & 45 & 22 & 23 & 5 & 0 & 5 & 22 \\
\hline 2 & 45 & 17 & 28 & 5 & 1 & 4 & 18 \\
\hline 3 & 45 & 21 & 24 & 5 & 1 & 4 & 22 \\
\hline 4 & 45 & 25 & 20 & 5 & 0 & 5 & 25 \\
\hline 5 & 45 & 22 & 23 & 5 & 0 & 5 & 22 \\
\hline 6 & 45 & 16 & 29 & 5 & 0 & 5 & 16 \\
\hline 7 & 45 & 18 & 27 & 5 & 2 & 3 & 20 \\
\hline 8 & 45 & 23 & 22 & 5 & 1 & 4 & 24 \\
\hline 9 & 45 & 20 & 25 & 5 & 1 & 4 & 21 \\
\hline 10 & 45 & 19 & 26 & 5 & 0 & 5 & 19 \\
\hline
\end{tabular}

\begin{tabular}{|c|c|}
\hline $\begin{array}{c}\beta_{y} \\
\text { common }\end{array}$ & $\begin{array}{c}\beta_{r} \\
\text { rare }\end{array}$ \\
\hline 0.285 & 0.715 \\
\hline 0.377 & 0.623 \\
\hline 0.321 & 0.679 \\
\hline 0.247 & 0.753 \\
\hline 0.285 & 0.715 \\
\hline 0.366 & 0.634 \\
\hline 0.500 & 0.500 \\
\hline 0.294 & 0.706 \\
\hline 0.335 & 0.665 \\
\hline 0.325 & 0.675 \\
\hline
\end{tabular}

Figure 1. The Results of the 20 Trials in the Frequency Dependant and Frequency Independent Selection of Wild Bird'S Investigation. 


\begin{tabular}{|l|c|}
\hline & $\begin{array}{l}\text { Median } \boldsymbol{\beta} \\
\text { value }\end{array}$ \\
\hline $\begin{array}{l}\beta, \text { rare } \\
\text { yellow 0.1 }\end{array}$ & 0.679 \\
\hline $\begin{array}{l}\beta, \text { common } \\
\text { red 0.9 }\end{array}$ & 0.321 \\
\hline $\begin{array}{l}\text { ro } \\
\text { common } \\
\text { yellow } \mathbf{0 . 9}\end{array}$ & 0.334 \\
\hline $\begin{array}{l}\boldsymbol{\beta}, \text { rare } \\
\text { red } \mathbf{0 . 1}\end{array}$ & 0.666 \\
\hline
\end{tabular}

Figure 2. The Median of $\beta$ Values Obtained from the Results of the Trials.
In the trials where yellow was common and red was rare $\beta y$ values ranged from 0.247 ( 3 decimal places) to $0.500 \beta \mathrm{r}$ values ranged from 0.500 to 0.753 and where red was common and yellow was rare $\beta r$ values ranged from 0.241 (3 $\mathrm{dp)}$ to 0.377 and $\beta y$ ranged from 0.623 to 0.759 . The median of the $\beta$ values are shown in figure 2 and the prey frequencies are shown in figure 3.

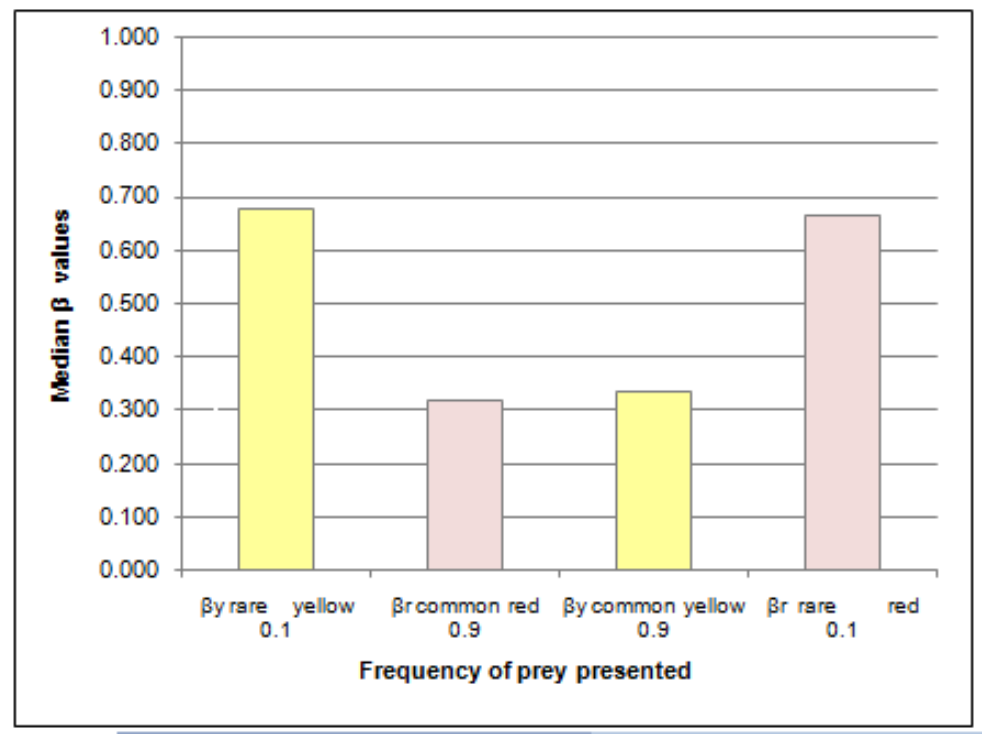

Figure 3. The Median $\beta$ Values Obtained for Prey Frequencies for By Rare, $\beta y$ Common, $\beta r$ Rare and $\beta r$ Common.

The median values for prey frequencies for $\beta y$ rare is 0.1 , $\beta y$ common is $0.9, \beta r$ common is 0.9 and $\beta r$ rare is 0.1 . There is no significant different between $\beta y$ yellow rare and $\beta \mathrm{r}$ red rare median.

Mann-Whitney $U$ test was used to test the significance of these differences in data. Results for frequency-dependent selection (comparing $\beta \mathrm{r}$ common with $\beta \mathrm{r}$ rare) and frequency-independent selection (comparing $\beta y$ rare with $\beta \mathrm{r}$ rare) are shown in table 1. Asterisk denotes statistical significance.

Table 1. Results of the Mann-Whitney U Test to Test the Significance of the Data Collected.

\begin{tabular}{lllll}
\hline B statistics compared & $\begin{array}{l}\text { Critical value at 5\% } \\
\text { level of significance }\end{array}$ & Test statistic $(\mathbf{U})$ & Probability & Conclusion \\
\hline$\beta \mathrm{r}$ rare with $\beta \mathrm{r}$ common & 23 & $0^{*}$ & Significant $\mathrm{P}<0.05$ & $\begin{array}{l}\text { Null hypothesis rejected. } \\
\text { Significant frequency-dependant selection. }\end{array}$ \\
$\beta y$ rare vs $\beta \mathrm{r}$ rare & 23 & $40^{*}$ & Not significant & $\begin{array}{l}\text { Null hypothesis accepted. } \\
\text { No significant frequency-dependant selection. }\end{array}$ \\
\hline
\end{tabular}

As the test statistic (U) is lower than the critical value for comparing $\beta \mathrm{r}$ common with $\beta \mathrm{r}$ rare, this shows that the null hypothesis can be rejected and that there is significant frequency-dependant selection present. On the other hand, the test statistic for $\beta y$ rare with $\beta r$ rare shows there is no significant frequency dependant selection due to it being higher than the critical value, therefore null hypothesis can be accepted.

\section{Discussion}

The results for $\beta \mathrm{r}$ common with $\beta \mathrm{r}$ rare show we can reject the null hypothesis that wild birds do not exhibit selection preferences due to the colour and frequency of the artificial prey, however, the null hypothesis can be accepted when in reference to frequency dependant selection. The wild birds showed no preference to which colour was rare, just that if that colour was the rare colour at the time, they would select it over the common colour.

The results show that significant frequency dependant selection was operating. In terms of if they prey was insects and survivability for the rare morphs, this could mean they could be eaten up to extinction. In terms of survivability, the 
ability to survive predation is in the frequency. On the other hand, if the prey was berries, then being chosen more for being rare could be a good thing because the birds excrete the seeds from the berries they eat, therefore possibly increasing the amount of the rare berries. This could however, happen to the point that the rare berries become the most common and the birds start choosing the other morphs because they are rarer, slowing the frequency growth of what was the rare morph.

It also important to raise that the prey was presented in high density. This means that it is possible that in lower density, more common berries are chosen because they are seen by the bird's more than rare morphs. If this happened in the case of insects, the more rare morphs might have a chance of surviving better than those of common morphs due to being spotted less by prey. This could be advantageous to the rare morphs. If this was in the context of berries, being rare and spotted less could be disadvantageous because then their seeds will not be spread via the birds.

The null hypothesis for the test for frequency dependant selection can be accepted. In this investigation there was no preference as to the colour of the prey. This could be because of the background colour of the apparatus used. The data shows that it does not matter which colour of prey is presented, the birds will still chose the rare morph of the morphs presented.

It is possible that variables could have an effect on the results. The species of birds which were part of the investigation may behave different from other species and it is possible that the results might be different if the location of the investigation is different. For example, in Haresnape's [2] investigation that was done in Oxfordshire showed evidence of frequency dependant selection whereas this investigation did not. This investigation took place in the Netherlands, Europe which is a different country with different species of birds. Time of year may also have an effect on the investigation. Different species of birds are more common in winter than in the summer which also brings up the point that the scope of the investigation is very limited and a more large scale investigation would have to be completed before a solid reliable conclusion could be made as to whether birds operate under frequency depend and frequency independent selection pressures.

\section{Conclusion}

The bird population which participated in the investigation showed evidence of operating under significant frequencydependant selection but not under significant frequency independent selection. If this investigation was to represent insects then the prey insects could be driven towards extinction via frequency-dependant selection leading to a loss of genetic diversity in that population. If this investigation represented berries than the rare morphs could grow to have more genetic diversity and it could also lead to the maintenance of polymorphism. Once the rare colour then becomes common, the birds would be likely to switch to the colour that is then rare and their selection would be repeated. This is not always the case though, in Allen, JA experiment, the birds tended to favour the common colour. [5]

If there are fluctuations in selection pressures due to location or species of birds, then that could help maintain genetic diversity in prey population.

\section{References}

[1] The Open University S317 (2015) accessed 8th march 2015. Available at:

https://learn2.open.ac.uk/mod/subpage/view.php?id=745379.

[2] Frequency-dependent and frequency-independent visual selection of red and yellow dough balls by wild birds in an Oxfordshire garden and evolutionary implications for potential prey populations. Haresnape 2015, The Open University - Accessed 8th March 2015 - Available: https://learn2.open.ac.uk/pluginfile.php/1688758/mod_resourc e/content/4/Haresnape\%202015.pdf.

[3] Allen, J. A. (1976) further evidence for a postatic selection by wild passerine birds - 9:1 experiments, Heredity 36(2), 173180.

[4] Allen J. A. Further evidence for apostatic selection by wild passerine birds: training experiments. Heredity (Edinb) 1974 Dec; 33(3):361-372.

[5] Allen J. A. Further evidence for apostatic selection by wild passerine birds -9:1 experiments. Heredity (Edinb) 1976 Apr; 36(2):173-180.

[6] Kettlewell, H. B. D. (1956) further selection experiments on industrial melanism in the Lepidoptera, Heredity 10,287-301.

[7] Manly, B. F. J. (1985) the Statistics of Natural Selection, Chapman and Hal.

[8] Allaboutbirds. org, 2015. Available at: https://www.allaboutbirds.org/guide/browse.

[9] Allen J. A. Frequency-dependent selection by predators. Philos Trans R Soc Lond B Biol Sci. 1988 Jul 6;319(1196):485-503.

[10] S. MERILAITA, 2006. Available at: http://citeseerx.ist.psu.edu/viewdoc/download?doi=10.1.1.385 $.4618 \&$ rep $=$ rep $1 \&$ type $=$ pdf. 